\title{
La integración desde la práctica: criterios y denominadores comunes para la cooperación sectorial ${ }^{1}$
}

\author{
The Integration from Practice: Criteria and Common \\ Denominators for Sectorial Cooperation
}

Hernando Zabala SALAZAR

\begin{abstract}
Resumen
La integración, en sus diferentes modalidades, no sólo representa un principio del cooperativismo mundial, sino que se ha constituido, con el tiempo, en el modelo empresarial más sostenible dentro de un mundo en permanente cambio. Las diferentes manifestaciones históricas de esta condición particular del cooperativismo es el tema que se desarrolla en este artículo de reflexión. Sobre la base de una revisión de diferentes experiencias exitosas (europeas y americanas), se identifican unas determinadas características que hacen exitoso el movimiento cooperativo, independientemente de sus configuraciones geográficas o sectoriales. Este producto forma parte de la línea de investigación en economía solidaria (2012) del grupo de investigación Ecosol de la Fundación Universitaria Luis Amigó, sede Medellín.
\end{abstract}

Palabras clave: cooperación, intercooperación, integración, sector, sistema cooperativo.

\section{Abstract}

Integration, in its various forms, is not only a global cooperative principle, but it has become, over time, in the most sustainable business model in an ever changing world. The various historical manifestations of this particular condition of the cooperativism is the subject taking place in this article. Based on a review of different successful experiences (European and American), certain characteristics that make successful the cooperative movement are identified, regardless of their geographical or sectoral configurations. This product is part of the research line in solidary economy (2012) of the research group Ecosol of the Fundación Universitaria Luis Amigó, Campus Medellín.

Keywords: cooperation, inter-cooperation, integration, sector, cooperative system.

Descriptores alfanuméricos (JEL codes): J540-Labor Managed Firms; F150-Economic Integration: O100-Economic Development.

Recibido: 5 mayo del 2012 Aprobado: 30 de junio del 2012

1 Artículo de reflexión derivado de la línea de investigación en economía solidaria (2012) del grupo de investigación Ecosol de la Fundación Universitaria Luis Amigó, sede Medellín.

Especialista en Derecho Cooperativo. Profesor de la Fundación Universitaria Luis Amigó, sede Medellín. Correo electrónico: hzabala@funlam.edu.co

Cómo citar este artículo: Zabala Salazar, H. (2012). La integración desde la práctica: criterios y denominadores comunes para la cooperación sectorial. Revista Cooperativismo \& Desarrollo, 20(101), 112-131. 


\section{Presentación}

Parodiando a un autor anónimo, el maestro Francisco Luis Jiménez enseñaba que "Los cooperativistas somos como ángeles de una sola ala, que sólo podemos volar abrazándonos unos a otros". Con esto hacía referencia al hecho de que el sector cooperativo sólo alcanza esta dimensión cuando sus unidades individuales actúan permanentemente con base en la práctica de la integración y la intercooperación.

Pero no sólo es por el hecho de que las cooperativas alcanzan una cierta capacidad numérica o de cobertura territorial o de actividades económicas que les exige algún tipo de coordinación, es la condición misma de encontrarse conviviendo con sectores económicos que le compiten, le ponen barreras que buscan subordinarle, lo que lleva al movimiento a adoptar la forma de federalización empresarial y concentración económica, con el fin de sobrevivir. De lo contrario, estando aisladas, las unidades económicas del sector sólo serían mecanismos complementarios y de intermediación de las operaciones nacidas y controladas por los sectores que le compiten (privado lucrativo y estatal). Para expandir la utopía cooperativista y perpetuarse, el movimiento debe ser uno, debe actuar como un sistema.

Pero esto nos lleva a intentar definir de entrada cómo las cooperativas experimentan las unificaciones y concentraciones. En principio hay dos procesos simultáneos de acercamiento entre ellas: el primero, relacionado con su naturaleza; el segundo, con su intervención en la economía. Esto es, en el nivel macroeconómico se repite la estruc- tura base de una cooperativa: la coexistencia de una asociación y una empresa. Como asociación, expresa el deseo del grupo social que la conforma, en la pretensión de una vida mejor; como empresa, agrupa la potencialidad productiva o consumidora de sus miembros, para hacer eficiente su trabajo o sus ingresos, asegurando así aquel ideal de buen vivir. Asimismo, en el nivel macroeconómico, la federalización asegura el principio de defensa de la naturaleza (de las aspiraciones sociales del movimiento) y la intercooperación asegura el desarrollo de sus negocios de una manera coordinada. Lo que llamamos integración es la expresión de la federalización y asociatividad; lo que llamamos intercooperación es la expresión de lo empresarial y de la sostenibilidad económica.

En todo caso, la unificación de las cooperativas es un fenómeno inherente a ellas, y si no se verifica compromete su propia existencia.

Tan consustancial es a la filosofía cooperativa el federalismo, que tan pronto como en un determinado país las entidades cooperativas alcanzan cierta densidad numérica tienden a establecer entre ellas lazos y relaciones más o menos estrechas, según su actividad (agrícola, consumo, vivienda, trabajo, crédito, etc.), radio de acción (local, territorial, nacional o sus afinidades ideológicas o políticas), formando el Movimiento Cooperativo y constituyendo en el cuadro económico determinado el Sector Cooperativo (Del Arco, 1977, p. 57).

De modo que los modelos de unificación del cooperativismo se dan como integración económica (generalmente de 
carácter horizontal) y como integración social (generalmente de carácter vertical). En la segunda, puede expresarse la integración para la defensa y el desarrollo (que es lo que en otros esquemas empresariales se denomina gremialidad).

Para efectos del presente ensayo, nos preguntamos acerca de expresiones históricas exitosas en ambas dimensiones. Pero hay que entender que así como una cooperativa para ser exitosa debe comprender un alto grado de sentido de asociatividad combinado con un alto grado de desarrollo empresarial, también un determinado movimiento cooperativo debe combinar exitosas experiencias de intercooperación con una fuerte estructura de federalización. No puede haber parcialidad en el entendimiento del éxito. Por eso las experiencias de importantes desarrollos de coordinación económico necesariamente están mediatizadas con experiencias de alto nivel de coordinación social —y política, obviamente.

Con base en el estudio que el autor realizó para Confecoop, Antioquia, sobre potenciamiento del sistema de intercooperación en Antioquia, podemos acercarnos a importantes experiencias en Europa, América del Norte y Latinoamérica.

\section{Tipos de integración}

De la experiencia histórica podemos deducir dos grandes tipos de unificación —o de coordinación de acciones- del movimiento cooperativo: el orden federado (la naturaleza) y el orden económico (la actividad). En términos sociológicos, podemos diferenciarlas como integración subjetiva — relacionada estrictamente con el carácter de cooperativa y sus condiciones particulares de existencia como ente jurídico diferenciado y especial- e integración objetiva - relacionada con la intervención de la cooperativa en la vida económica, afectada por las racionalidades propias de todo fenómeno económico.

Antes de que se produjeran estudios avanzados en estas materias (que sólo iniciaron en 1932 y se fueron perfeccionando hasta 1980) solamente se hablaba de integración en los niveles de verticalidad y horizontalidad. Con el desarrollo de movimientos de gran trascendencia -en Inglaterra, Francia, Suecia, Alemania, Canadá, Estados Unidos y España- se fue perfeccionando el modelo teórico y sus orientaciones, con el fin de mejorar las prácticas de correlación. En estos últimos sentidos, debemos mucho al profesor Henri Desroche (1977) y a los múltiples teóricos de la experiencia cooperativa de Mondragón.

Se entendió, desde entonces, por ejemplo, que la integración económica debía producirse de una manera natural, así no existieran integraciones institucionales, pero que estas últimas eran básicas para orientar el desarrollo de las primeras. Asimismo, se descubrió que un movimiento que sólo presta atención a las integraciones subjetivas -institucionales o sociales o de naturaleza o verticales o de gremialidadse ve reducido en su desempeño y nunca avanza hacia su conformación como sector económico. Las integraciones horizontales -o económicas o de intercooperaciónson el principal medio para el crecimiento del movimiento, en las perspectivas macro y microeconómica. 
Desde una posición académica, Alejandro Martínez Charterina, por muchos años director del Centro de Estudios Cooperativos de la Universidad de Deusto (Bilbao), explicó acertadamente los diferentes aspectos relacionados con el tema de la integración cooperativa. Para este pensador español existe una terminología variada y poco precisa respecto del concepto en análisis: relaciones intercooperativas, intercooperación, intercolaboración cooperativa, concentración, integración, federalismo, agrupación, etcétera, que constituyen expresiones frecuentemente superpuestas. Sin embargo, defiende esa variabilidad en el sentido de que para la doctrina cooperativa la intercooperación es un concepto unívoco: se trata de encaminar al cooperativismo en la dirección del cambio de estructuras, se trata de hacer "movimiento cooperativo". Es una vocación a la que están llamadas las cooperativas por el hecho de serlo. Para Martínez Charterina, la integración tiene diferentes fines, especialmente de tipo moral-social y de tipo económico.

Las manifestaciones de integración de tipo social presentan claramente funciones de representación y defensa del cooperativismo; esto es, una primera misión de la integración es conseguir tales propósitos, transcendiendo "la esfera de lo formal para convertirse en tribuna y voz que influya en los estamentos políticos y sociales de toma de decisiones que puedan afectar directamente al propio cooperativismo" (Martínez, 1990, p. 31).

Pero otro aspecto importante de la integración, en este nivel, lo constituyen las funciones de comunicación dentro y fuera del movimiento, en torno a la creación de espacios para el intercambio de experiencias, la profundización acerca de su razón de ser y sus potencialidades y el establecimiento de pautas comunes de actuación, así como el desarrollo de actividades de información, propagandización y expansión del pensamiento y modo de obrar cooperativistas. Finalmente, también se consideran elementos de integración social y moral todas aquellas acciones que tienen que ver con el mejoramiento del quehacer cotidiano asociativo o empresarial —asistencia técnica, educación, fiscalización, capacitación, etcétera-, facilitando el ejercicio doctrinario y administrativo de las unidades individuales y contribuyendo también a crear espacios de reflexión y planeación.

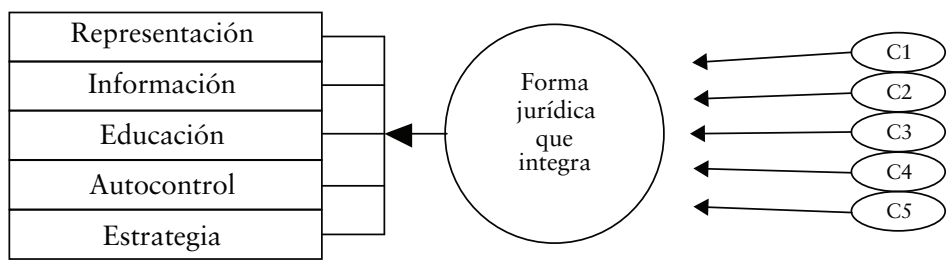

Figura 1. La integración social y moral

Fuente: el autor 
Así pues, todos los movimientos cooperativos nacionales o regionales atraviesan por la etapa de la integración social y moral pero, para su consolidación, deben alcanzar la etapa de la integración económica, partiendo del postulado de que la cooperativa aislada se enfrenta a un mundo que le es adverso en métodos y doctrinas: el mundo del mercado capitalista.

En orden a responder a esta amenaza que les envuelve, las cooperativas se integran en principio para eliminar la intermediación, mediante centrales diversas de comercialización. También lo hacen mediante uniones de servicios técnicos, centros de investigación en tecnología, centrales financieras y sistemas de especialización productiva. Luego, siguiendo los análisis de José María Ormaechea U. (1988, p. 4), logran coordinación en sus procesos de entrada y salida de factores productivos - constituyendo circuitos y redes empresariales-, para llegar a conformar un grupo empresarial. Todas estas fases pretenden, en suma, una alta racionalización empresarial del proceso económico.

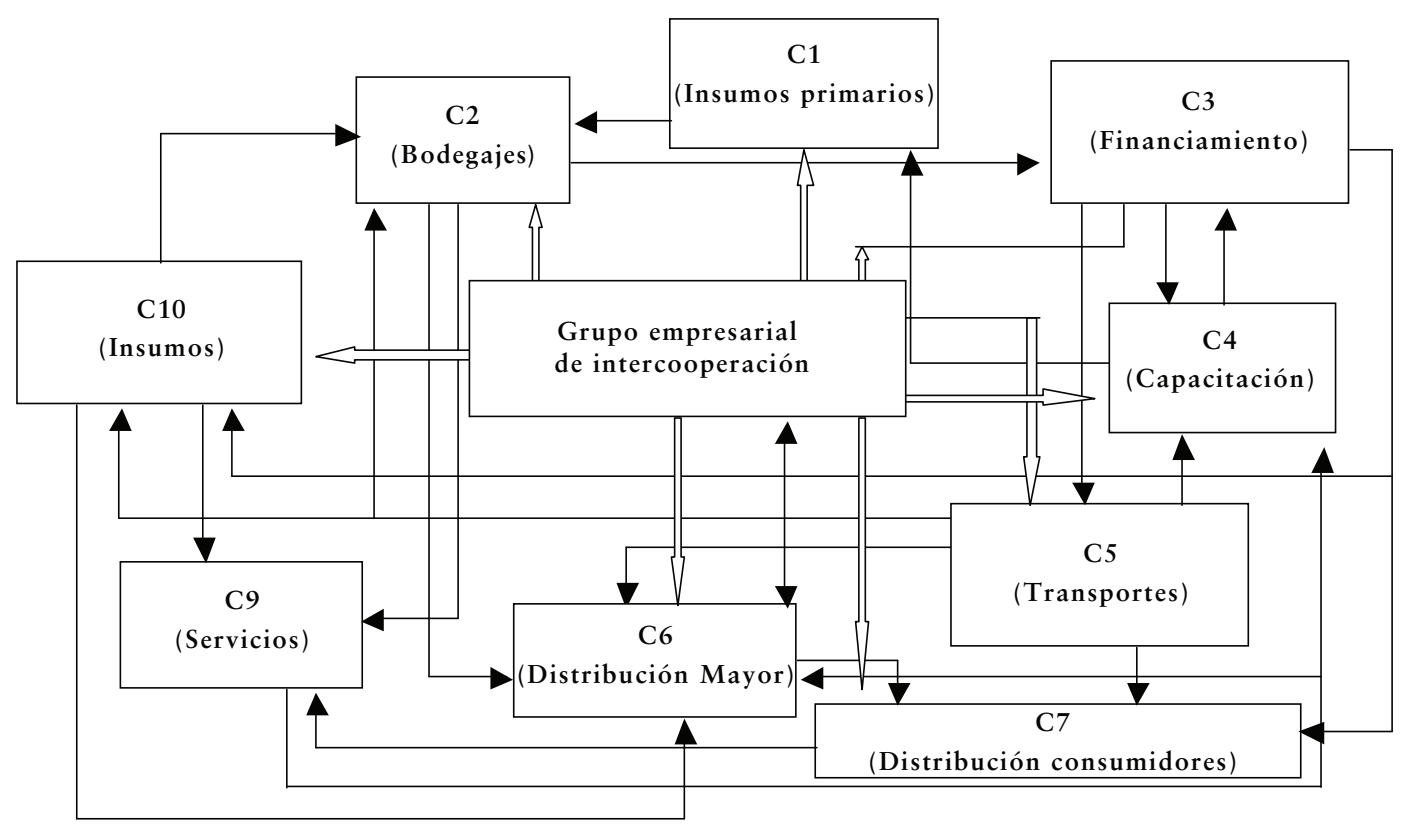

Figura 2. La integración económica

Fuente: el autor

Desde los primeros tiempos del cooperativismo moderno se han creado organismos diversos para atender, básicamente, los objetivos subjetivos - políticos, de representación o de mejoramiento de des- empeño microeconómico一, pero también se ha avanzado hacia la búsqueda de los fines económicos, llegando a constituirse verdaderas multinacionales cooperativas. Sin embargo, estas realizaciones están 
muy lejos, cuantitativa y cualitativamente, de las generadas por la dinámica de la economía de las sociedades capitalistas, por lo que queda un amplio camino que recorrer en esta dirección.

\section{Las integraciones económicas, objetivas o de intercooperación}

Por la importancia que han adquirido las integraciones objetivas, empezaremos con su explicación y descripción. Algunas de estas experiencias son ampliamente conocidas, desde un punto descriptivo; de otras apenas se tienen ideas generales sobre su desempeño.

\section{Los modelos originales de intercooperación}

La organización cooperativa

de los consumidores de Gran Bretaña

El movimiento cooperativo de Inglaterra, a partir de la experiencia de los Pioneros de Rochadle, avanzó enormemente a finales del siglo XIX y durante todo el siglo XX, hasta cubrir, en sentido demográfico, las dos terceras partes de la población. La historia de este movimiento demuestra que se ha sostenido organizadamente, partiendo de lo pequeño y de lo local. Las sociedades cooperativas locales son independientes unas de otras, aunque tienen una asociación común en la Sociedad Cooperativa Mayoritaria y las Uniones. Este modelo tiene las siguientes características básicas:

a. Las cooperativas de menudeo no se restringen a una sola tienda, pero se limitan territorialmente a una o dos localidades. b. Las tiendas centrales constituyen un almacén grande, con departamentos especializados y servicios de restaurante, lavandería, exequiales, etcétera.

c. La comercialización de ropa, calzado y muebles no es tan eficaz, por lo que tiene que manejarse en tiendas especiales para que puedan rendir utilidades.

d. La Unión Cooperativa es una Confederación de Sociedades locales y nacionales, que existe para defender el movimiento y orientar su política.

e. La estructura del movimiento cooperativo británico cubre un amplio campo de procesos de producción de bienes y servicios, para lograr proveer las necesidades diarias en forma regular y con calidad.

f. Todas las tiendas cooperativas negocian con comestibles; en poblaciones grandes la gente compra sus muebles y ropa en la tienda central, mientras que en las zonas rurales la distribución no sólo se da por medio de las entregas ordinarias, sino también a través de tiendas viajeras.

g. Las sociedades de base se surten de la Sociedad Cooperativa Mayorista, la cual se ha dedicado a desarrollar sus propios productos; su objetivo es realizar la cadena productiva completa, desde la compra al productor hasta la puesta en el mostrador.

h. La Sociedad Cooperativa Mayorista (cws) comprende, a su vez, un conjunto de unidades económicas del sector primario y secundario de la economía, que garantizan la demanda de las cooperativas de base. 
El modelo contempla entidades de cobertura nacionales, tales como el banco cooperativo, la sociedad de seguros, el sistema de auditoría, imprentas, periódicos, instituciones educativas, empresas transportadoras y unidades económicas ubicadas en otras áreas logísticas. Su representación política parte de los Congresos de la Unión de Cooperativas de Inglaterra (que se realizan cada cuatro años) y se adelanta mediante la acción del Partido Cooperativista Independiente.

\section{El sistema bancario cooperativo de Alemania}

Es un sector con un alto grado de cohesión, en el cual todos sus integrantes se afilian (por ley) a una Federación de Cooperativas, respetan los principios de regionalidad entre las cooperativas de base y de subsidiaridad entre los tres pisos del sistema cooperativo. Manejan la misma imagen corporativa y son sujetas a una auditoría externa por parte de las propias federaciones de cooperativas.

Los bancos cooperativos son, desde el punto de vista operativo, instituciones financieras con una amplia gama de operaciones permitidas, que representan, en unión con las cajas de ahorro, más del $80 \%$ de la banca universal de Alemania.

Los principios básicos que ordenan el sector y dinamizan la intercooperación son:

1. El principio de la subsidiaridad que rige entre los tres niveles mencionados (local, regional y nacional). Así pues, los bancos centrales sólo efectúan funciones que no pueden o - por razones del costo - no deben llevar a cabo las cooperativas de base.
2. El principio de regionalidad, según el cual las cooperativas se distribuyen geográficamente el mercado entre ellas y hacen competencia a la competencia - es decir, a la banca privada y a las cajas de ahorro- y no a ellas mismas. La observación del principio regional permite que todas las cooperativas cuenten con una misma imagen corporativa -incluyendo logotipos, colores, etcétera-, lo que manifiesta hacia afuera que se trata de una familia unida de cooperativas individuales.

El sistema bancario cooperativo se complementa con las instituciones del nivel regional, que atienden las cooperativas de base en sus necesidades de refinanciación y requerimientos de liquidez. Los bancos centrales existentes brindan servicios para los bancos locales, evitando cualquier tipo de competencia y persiguiendo el principio de la subsidiaridad.

Finalmente, el sistema bancario cooperativo alemán es complementado por otros tipos de cooperativas con servicios financieros, así: a) la mutual de ahorro para la vivienda - la más grande de Europa-, otorga crédito hipotecario de muy largo plazo e interés muy bajo, en muchos casos con tasa fija; b) empresas de seguros, leasing, de inversión, consultoría y bancos hipotecarios, entre otras; c) las Federaciones Regionales de Auditoría, que agrupan las cooperativas de base independientemente de su actividad -transporte, producción, intermediación financiera, etcétera-y las Federaciones Especializadas de Auditoría. 
Entre estas diferentes empresas se desarrollan sinergias: las cooperativas de base promueven la venta de contratos de ahorro para la mutual y eventualmente pueden llegar a cofinanciar la vivienda; promueven, de la misma manera, los productos de las empresas de seguro y de inversiones.

A nivel nacional y para fines básicamente de representación y defensa ante las autoridades estatales, existe la Deutscher Genossenschafts und Raiffeisenverband (DGRV) como confederación de todos los tipos de cooperativas y las federaciones nacionales especializadas según la actividad de sus miembros. En la cúspide del sistema se encuentra el banco central cooperativo de toda Alemania.

\section{La socialización agraria de Israel}

La organización cooperativa en Israel presenta distintas variantes, entre las cuales se destacan: el modelo Hevrat Ovdim, el modelo Kibbutz y el modelo Moshav.

Pero el cooperativismo en Israel floreció inicialmente gracias al empeño de un grupo de inmigrantes idealistas, quienes procedían de Europa Oriental y fundaron el primer kibbutz en 1909. Constituyeron así una forma cooperativa de producción colectiva, una comunidad voluntaria en la que el individuo toma una libre decisión de desarrollar su vida con base en principios de cooperación.

Modelos de intercooperación financiera El Movimiento Desjardins en Québec (Canadá)

El Movimiento Desjardins fue creado en 1900 para brindar a los quebequenses una herramienta financiera que les permitiera acceder al ahorro y al crédito, además de posibilitar el desarrollo de la comunidad; surgió como respuesta a la crisis económica por la que atravesaba esta región, y como solución al mejoramiento de la vida de los trabajadores. En los primeros años del siglo XXI, este movimiento ya contaba con más de 5.800.000 miembros, 13.000 dirigentes y 38.000 empleados en la región del Québec. Ello implica que poseía una tasa de penetración demográfica del 68,9\% en la provincia. Además de contar con un fondo de garantías - que hace las veces de reserva común-y filiales, se cuenta con sociedades promotoras de valores cooperativos y de cooperación internacional, como son el Instituto Cooperativo Desjardins, que presta servicios de capacitación para adultos; la Sociedad Histórica y fundadora Desjardins, órgano de vocación artística y cultural, y la Sociedad de Desarrollo Internacional (DID), la cual es una organización comunitaria de ayuda internacional.

\section{Las uniones de crédito en Estados Unidos}

De la experiencia alemana y canadiense se tomaron en cuenta diferentes aspectos para establecer un sistema de cooperativas rurales de crédito en Estados Unidos, conocidas como Credit Unions. Como una extensión lógica de uniones en vía de desarrollo y una necesidad, en 1971 se creó el Concilio Mundial de Uniones de Crédito (woccu), que a finales del siglo xx representaba 85 movimientos nacionales con casi 90 millones de miembros. El Concilio Mundial es un cuerpo repre- 
sentativo, un proveedor de servicios y un foro para el intercambio de información.

Las uniones de crédito, los bancos de ahorro mutuo y otras asociaciones de ahorro no lucrativas, son parte importante del sistema financiero en Estados Unidos, con depósitos que forman parte de la oferta monetaria de ese país. Como subsector, copan el 15\% del mercado financiero, el cual es sólo superado por la banca comercial.

\section{El Sistema Integrado de Crédito} Cooperativo de Río Grande del Sur (Sicredi)

Sicredi es una red de cooperativas de crédito estructuradas en centrales estatales y a su vez accionistas exclusivas de un banco cooperativo, el Bansicredi, el más grande banco privado del Brasil. Ya al finalizar el siglo xx, el sistema se constituía por 98 cooperativas de base, con 401 agencias, cuatro centrales estatales y un banco cooperativo. Para ese entonces, Sicredi hacía presencia en nueve estados del Brasil.

El sistema es administrado con fundamento en los siguientes principios de gestión:

- Alianzas.

- Economía de escala.

- Administración participativa.

- Participación de los empleados.

- Selección cuidadosa y capacitación permanente de los recursos humanos.

- Viabilidad económica.

- Integración con la comunidad.

- Gestión de riesgo.

- Direccionamiento del crédito a los requerimientos y las necesidades de los asociados.
- Autocontrol.

- Fondo de garantías de crédito.

- Administración financiera.

\section{Modelos de intercooperación productiva}

\section{El Núcleo Cruz Azul de México}

El llamado Núcleo Cooperativo Cruz Azul es un conglomerado de cooperativas existente en México, asentado especialmente en los estados de Oaxaca e Hidalgo. Independientemente del fenómeno Cruz Azul, en este país, con base en tal experiencia, se han formado numerosos grupos y circuitos económicos cooperativos de producción. Se destacan los ingenios azucareros, la producción de cervezas, extractoras de material minero, salinas, cinematografía, pesca, entre otras.

De entre todos los grupos cooperativos el más promocionado ha sido el Núcleo Cruz Azul, que tiene como centro principalmente a los antiguos municipios de Jasso y Lagunas, que hoy han adoptado el nombre de "Ciudad Cooperativa Cruz Azul" y "Ciudad Cooperativa Lagunas”, respectivamente. En estas poblaciones viven la mayoría de los asociados trabajadores de las cooperativas del Núcleo, en urbanizaciones construidas y administradas bajo el régimen cooperativo, con jardines infantiles, escuelas básicas y centros de formación técnica de base cooperativa; también disponen de centros de asistencia en salud, campos deportivos, restaurantes y centros comerciales de propiedad del conglomerado cooperativo. Los campesinos que habitan los alrededores de las 
ciudades tienen derecho a participar de los servicios cooperativos de educación, salud y recreación. Los asociados trabajadores disfrutan de todos los servicios de previsión y seguridad social, incluidos fondos de ahorros, fondos de retiros, seguros mutuales y seguros de vida.

Rosendo Rojas Coria (1989, p. 90) argumenta que estos grandes logros no se alcanzaron sin sacrificios, como consecuencia de que en sus inicios el Núcleo Cooperativo no contaba con recursos financieros y luchaba contra la hostilidad de los competidores, asegurando su futuro sólo en el entusiasmo de sus asociados.

\section{La Corporación Cooperativa de Mondragón}

Este movimiento, iniciado a mediados de los años cincuenta del siglo xx por un pequeño grupo de trabajadores, engloba actualmente a más de 87.000 socios trabajadores, agrupados en empresas que se extienden desde el Valle de Leniz, por todo el país Vasco y Navarra. Su núcleo central lo forman una centena de cooperativas industriales que fabrican desde máquinas herramientas hasta bicicletas y una decena de cooperativas agroalimentarias que producen desde conservas vegetales hasta lechugas de invernadero. Ulgor, la primera cooperativa en fundarse, ha contado en su nómina con más de 5.000 socios trabajadores; es una de las mayores cooperativas industriales del mundo occidental y uno de los principales fabricantes españoles de refrigeradores, lavadoras y estufas.

Desde el punto de vista productivo, la Corporación Cooperativa de Mondragón (MCC) está dividida en tres grandes grupos: industrial, financiero y de distribución. El primero comprende todas las empresas dedicadas a los procesos de transformación industrial en las áreas de componentes y servicios industriales, hogar y construcción; entre ellas se destaca el Grupo Fagor. El segundo son empresas de complementación financiera al servicio de las demás entidades de MCC y de sus trabajadores, con extensión a la comunidad; al frente de ellas se encuentra la Caja Laboral Popular. El tercero se encarga de la comercialización de los productos, de la adquisición de los productos necesarios para la industria propia y la distribución de artículos de consumo a la población; su centro es el Grupo Eroski.

Adicionalmente se encuentran otras instituciones de superestructura, especialmente relacionadas con la educación y la investigación, cuyo eje es la Universidad Cooperativa de Mondragón.

De manera sucinta, el proceso de intercooperación puede descubrirse alrededor de la producción de electrodomésticos en Fagor, tal como lo indica la figura 3. 


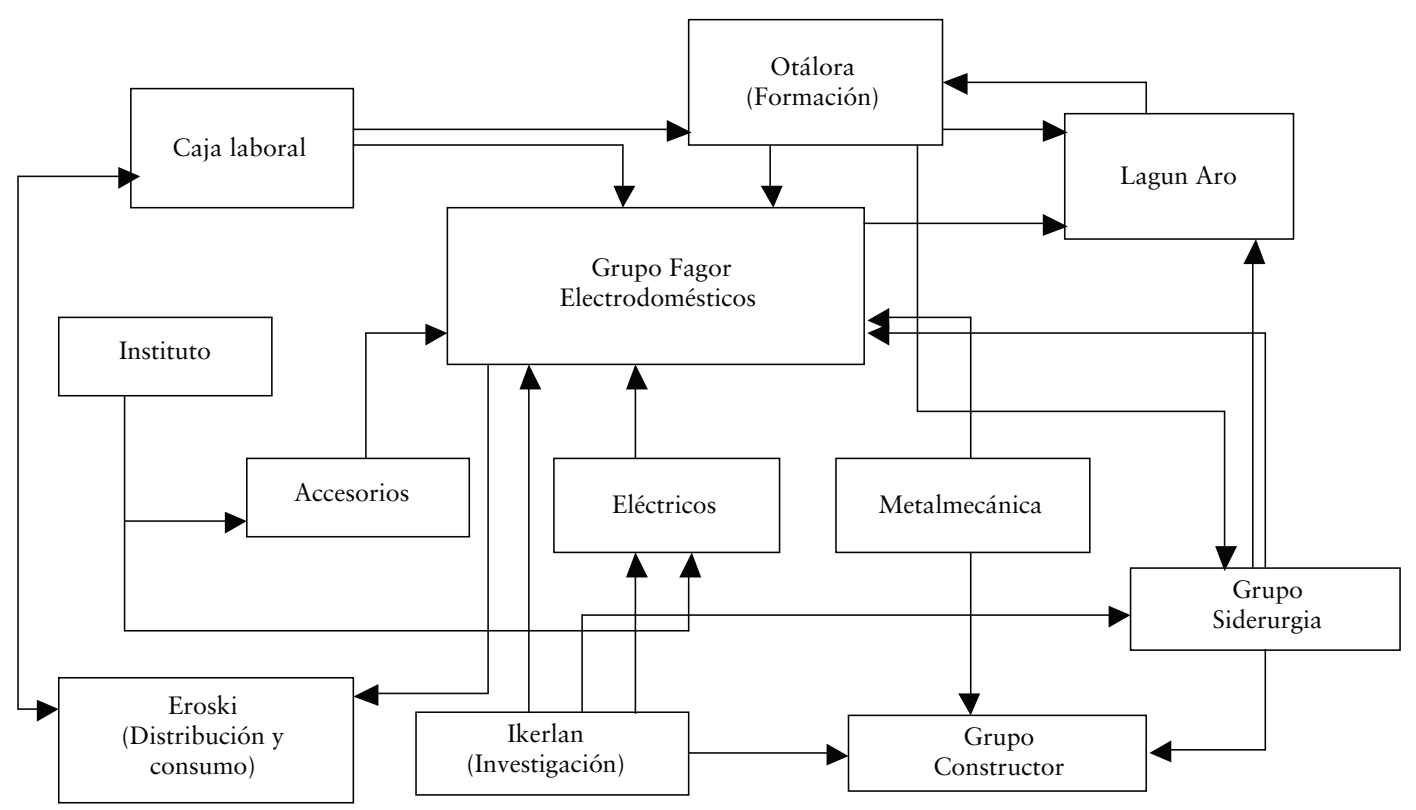

Figura 3. El circuito de la intercooperación del Grupo Mondragón

Fuente: el autor

\section{Modelos de intercooperación territorial}

\section{La cooperación sueca}

El Movimiento Cooperativo se inició en Suecia en unas condiciones en extremo modestas. Eran muchas las dificultades que había que superar y no faltaron en los primeros tiempos algunos fracasos. Las distintas formas de actividad cooperativa se han ido extendiendo y consolidando progresivamente hasta convertirse en un factor de primera importancia en la vida comunitaria. Los objetivos del Movimiento Cooperativo sueco pueden resumirse así:

a. Distribuir los bienes de consumo y los servicios que mejor satisfagan las necesidades de los consumidores y facilitar a los consumidores informaciones que les ayuden a organizar su economía individual y familiar. b. Difundir informaciones sobre todos los aspectos de la vida social y económica que tengan un interés especial para los consumidores.

c. Proteger los intereses de los consumidores en relación con el desarrollo general económico y social, especialmente en el campo de la legislación.

\section{El sistema productivo local de la Región Romaña en Italia}

Desde los años cincuenta la región Emilia-Romaña ha experimentado una expansión de su sistema económico y productivo, perfilándose como un ejemplo de desarrollo basado, fundamentalmente, en un tejido de pequeñas y medianas empresas. Su éxito se debe a varios factores que van más allá del aspecto puramente económico. En esta 
región se conjuga la existencia de una sociedad civil participativa con una fuerte inclinación empresarial, unos gobiernos progresistas y estables, y una equilibrada intervención pública.

La producción de Emilia-Romaña está basada en el sector primario. La agroindustria y la industria manufacturera representan los pilares de la economía regional, en oposición con el resto de las regiones avanzadas de Italia en las cuales el sector terciario ocupa el lugar central. Pero el pilar de la economía regional es su sistema descentralizado de pequeñas empresas especializadas, unidas por estrechos lazos de cooperación.

Este movimiento interviene en las diversas fases del ciclo económico: en la agricultura — con queserías, establos sociales, cooperativas de arriendo de tierras-, en la distribución —con cooperativas de consumidores y detallistas-, en la construcción - con grandes y medianas empresas-, en la industria y en los servicios.

La Emilia-Romaña es, en principio, conocida internacionalmente por los llamados distritos industriales y por una política pública regional innovadora en relación con las pequeñas y medianas empresas de la región. Una expresión particular de la experiencia de esta región italiana es la desarrollada en la provincia de Trento, por medio de la Federazione Trentina Della Cooperazione.

\section{Elementos caracterizadores de los modelos de integración económica}

Las experiencias de cooperación que se acaban de registrar presentan una serie de características comunes que comparten con cualquier grupo empresarial de naturaleza capitalista, con la gran diferencia de que sus valores agregados contribuyen a hacer realidad el ideal de la asociación cooperativa.

Estas características pueden estar representadas en dos grandes dimensiones: la primera, relacionada con la racionalidad productiva y la segunda representa los objetivos mismos del movimiento cooperativo.

\section{Características de la organización productiva}

Un inventario de estas tiene en cuenta las siguientes variables:

- Son economías de escala. Esto es, aprovechan la identidad en torno a la naturaleza cooperativa, para acceder al mercado de factores y de productos de forma integrada, bajando costos en la producción y en el consumo.

- Son experiencias de interconexión productiva. Esto es, crean una especie de sistemas económicos autónomos, que conectan diferentes unidades económicas (independientemente del sector al cual pertenezcan), estableciendo entre ellas una cierta división del trabajo, cadenas productivas y clústers cooperativizados.

- Generan altos valores agregados. Al producir la interconexión, actúan de manera especializada, generando mayor productividad. Asimismo, ello permite encontrar los recursos necesarios para avanzar en nuevos proyectos productivos con alta intervención tecnológica, constituyendo 
una variable que contribuye a elevar los valores agregados, los cuales se invierten de manera endógena.

- Creación de entidades de cobertura. Se descubre en la interconexión la presencia de procesos que pudieran ser coordinados empresarialmente, sobre todo para responder a fragilidades individuales o a necesidades colectivas en materia de cobertura de servicios sociales, creación de canales de comercialización, desarrollos tecnológicos, capacitación de talentos y financiamiento.

- Localización económica. Estas experiencias parten del reconocimiento de vocaciones productivas, caracterización del potencial productivo del territorio y aprovechamiento de las capacidades innovadoras de la gente. Por tanto, no son experiencias muy extendidas geográficamente, y ello permite crear identidad del proyecto. Esto está directamente relacionado con un tema que parece haber desaparecido con el neoliberalismo, pero que -en economía- es absolutamente determinante: la localización productiva, ya que lo global generalmente está relacionado con la adquisición de factores productivos subjetivos -especialmente los medios financieros, el conocimiento y la gestión- y la puesta de productos finales en los mercados externos, pero existen factores que son definitivamente locales y son los que aporta el proyecto cooperativo: el trabajo, el medio material natural y la asociatividad.
- Vinculación al desarrollo local. Desde el punto de vista de los efectos de la intercooperación, el valor agregado logra invertirse en el nivel local, generando distribución equitativa de la riqueza y produciendo externalidades que mejoran el posicionamiento del territorio.

\section{Características de la}

organización social cooperativa

Con la intercooperación, los ideales del cooperativismo se hacen más cercanos. A partir de ella, la utopía se hace realidad. Ello se demuestra en los siguientes logros alcanzados en las experiencias anteriormente registradas:

- Elevación de ingresos de los asociados. Sea en la condición de asociado-productor-trabajador o asociado-consumidor o asociado productor-proveedor, siempre se verifica que el proceso de interconexión eleva el nivel de remuneración, además de estabilizarlo.

- Mejoramiento de las condiciones de vida de los asociados. El crecimiento en el nivel de ingresos permite que el asociado pueda tener mayor acceso a los satisfactores de sus necesidades. Pero ese mayor acceso también lo garantiza el sistema, creando empresas de cobertura en los órdenes sociales, para consumo de las personas mediante sistemas de seguridad social, habitacional, recreacional, educativo, etcétera.

- Elevación del nivel de bienestar comunitario. Como es obvio, y en conjunción con el principio de preocupación por la comunidad, estos modelos reinvierten 
sus valores agregados no sólo entre los asociados, sino también hacia las comunidades que les circundan. Ya no se trata de una exigencia del mercado - para lograr su mejor posicionamiento- o de carácter coercitivo - para acceder a beneficios tributarios - sino que se convierte en una acción voluntaria y de extensión de la naturaleza humanista del cooperativismo.

- Desempeño administrativo. La intercooperación hace necesaria la estandarización de procesos administrativos, dirigidos por los contenidos de la naturaleza cooperativa. Ello hace posible la creación de políticas unificadas que mejoran el desempeño organizacional en temas tales como remuneraciones, formación del talento humano, acceso a mercados, desarrollos tecnológicos, financiamiento, etcétera.

- Grupo empresarial. Necesariamente la concurrencia de empresas lleva a la formación de grupos empresariales que se caracterizan por un desempeño administrativo estandarizado, la formación de una marca única - que da identidad de grupo-, el acceso centralizado a mercados de productos, financiamiento mutuo y relacionamiento integrado con otros sectores.

- Relaciones con el Estado. La intercooperación produce fortaleza económica, lo que se constituye en la mejor defensa. Así, el Estado se convierte en un aliado y no en un detractor, cuando este se encuentra dirigido por gobernantes que promueven el bienestar general y se afincan en el respeto a los derechos humanos por encima de cualquier otra consideración. El Estado no ve en el cooperativismo un simple comodín sino una fuerza coadyuvante en su plan de largo plazo. A su vez, el cooperativismo alcanza una fuerte influencia en el Estado, ya que su fuerza económica y social permite incidir en sus políticas y participar en sus órganos de representación.

- Gobernanza. Como consecuencia de los factores anteriores, el gobierno de las cooperativas también se hace más cercano al ideal de la cooperación. Los valores inculcados por los fundadores se hacen ciertos por medio de mecanismos idóneos de autocontrol y por la presencia de un nivel de vida más aceptable: los dirigentes son más transparentes, demócratas, solidarios, equitativos, responsables y honestos.

\section{Las integraciones sociales, subjetivas o de estructuras federadas}

Si seguimos los postulados de la teoría económica clásica, podemos decir que las integraciones económicas -en las cuales se incluyen cooperativas de base, centrales de servicios comunes, entidades de cobertura, organismos de coordinación económica, etcétera- son la infraestructura de los modelos exitosos del cooperativismo. Pero esta integración objetiva también requiere, sobre todo para mantener incólume la naturaleza y lograr una adecuada representación en la sociedad civil y en la sociedad política, una fuerte integración subjetiva, representando el principal componente de la superestructura cooperativa. 


\section{Experiencias reconocidas}

Algunos de los modelos referidos en el acápite anterior no necesariamente cuentan en su interior con una fuerte integración institucional - tales como los casos de MCC y los sistemas de intercooperación financiera-, pero se encuentran estrechamente ligados a sistemas de federalización regional o nacional. Asimismo, existen sistemas de gremialidad que por sí mismos no dominan los sistemas de intercooperación o apenas están en procesos de consolidación. Algunos de los ejemplos que involucramos en este texto son los siguientes: el sistema DGRV de Alemania, el sistema осв de Brasil, el modelo quebequense-canadiense y las integraciones del País Vasco.

\section{El sistema DGRV de Alemania}

La Confederación Alemana de Cooperativas es la organización de carácter nacional y la máxima federación rectora del sector cooperativo alemán. Cuenta con 5.300 cooperativas afiliadas, intervinientes en diferentes áreas productivas: agricultura, bancos, pequeña industria-comercio y servicios, con 789.000 empleados. En Alemania, una de cada cinco personas está asociada a una cooperativa, con 18 millones de miembros; además, hay más de 1.900 cooperativas en el ámbito de la construcción de viviendas, con aproximadamente tres millones de miembros.

La ley requiere que todas las cooperativas en Alemania sean auditadas cada año. El mandato de auditoría fue entregado a las cooperativas y federaciones regionales. Por tanto, las cooperativas están sujetas a las auditorías legales requeridas por estas asociaciones. Otra tarea fundamental de las federaciones es ayudar a las cooperativas, particularmente en relación con la gestión empresarial, cuestiones jurídicas y la organización de actividades de formación y capacitación. También ofrecen una amplia gama de diferentes servicios adicionales: asesoramiento procesamiento electrónico de datos y sistemas de gestión de la información, entre otros.

La DGRV integra a todos los grupos. En su calidad de organización paraguas del sistema alemán de cooperación, cubre los siguientes campos:

- Es la confederación nacional de auditoría para el sector cooperativo. Lleva a cabo auditorías de los bancos y las cooperativas a nivel nacional y regional.

- Como organización cúpula, es responsable de todos los asuntos del sector: política económica, jurídica y fiscal, comunes a todas las ramas de las cooperativas.

- Mantiene contactos con otras organizaciones e instituciones nacionales e internacionales.

- Se compromete en actividades de desarrollo cooperativo en todo el mundo. Tiene el mandato del sector para apoyar proyectos de desarrollo $\mathrm{y}$ asistencia internacional.

\section{La Integración de la осв del Brasil}

El cooperativismo brasilero logró su autonomía con la promulgación de la 
Constitución del 5 de octubre de 1988. A partir de la nueva Constitución, libre de la tutela del Estado, el cooperativismo brasilero amplió sus horizontes. La libertad para crear su propia institución financiera multiplicó las posibilidades de acción.

Tres o más cooperativas de base pueden constituir una central o una federación de cooperativas, consideradas de segundo grado, en las que cada cooperativa de base tiene un voto, independientemente del capital integrado, siendo también admitido el voto proporcional. Todas las cooperativas de base, centrales, federaciones y confederaciones, tienen un voto para elegir la directiva y el consejo fiscal de la OCE -Organización de las Cooperativas del Estado-, admitiéndose el voto proporcional. Esa organización congrega y representa todos los segmentos del cooperativismo en el respectivo Estado y presta servicios a sus afiliadas, conforme a los intereses y las necesidades de ellas. Las Organizaciones Cooperativas de cada Estado, ocE, tienen un voto en la elección de la directiva y el consejo fiscal de la осв (Organización de las Cooperativas Brasileras).

La representación del Sistema Cooperativista Nacional le corresponde a la ОСв, competiéndole principalmente:

a. Mantener la neutralidad política y la indiscriminación racial, religiosa y social.

b. Integrar todos los ramos de las actividades cooperativistas.

c. Mantener el registro de todas las sociedades cooperativas que, para todos los efectos, integran la осв. d. Mantener servicios de asistencia general al sistema cooperativo, sea en cuanto a su estructura social, sea en cuanto a los métodos operacionales y de orientación jurídica, mediante opiniones y recomendaciones.

e. Disponer de sectores consultivos especializados, según segmentos del cooperativismo.

f. Fijar la política de organización con base en las proposiciones surgidas de sus órganos técnicos.

g. Ejercer otras actividades inherentes a su condición de órgano de representación y defensa del sistema cooperativista.

h. Mantener relaciones de integración de la actual representación del Sistema Brasilero del Cooperativismo.

Desde la perspectiva organizacional, la осв ha alcanzado un desarrollo de grandes proporciones en los últimos veinte años, adoptando un esquema de intervención sobre el desempeño y desenvolvimiento de sus organizaciones afiliadas.

\section{La federalización canadiense}

Como ocurre con el caso alemán, en Canadá se produce un fuerte movimiento con base en cajas populares que operan servicios financieros, pero el cooperativismo tiene una amplia extensión en otras actividades y regiones diferentes a Québec.

La organización cúpula es el Consejo Canadiense de la Cooperación, fundado en Québec el 8 de febrero de 1946. Agrupa ocho consejos provinciales de cooperación que representan casi 12 
millones de miembros, y cerca de 4.000 cooperativas con activos superiores a 120.000 millones de dólares. En el 2008, el Consejo Canadiense de la Cooperación (CCC) y la Asociación Canadiense de Cooperativas (CCA) unieron sus energías y realizaron un solo congreso. Este congreso, que se realizó en Manitoba, fue trascendental, en tanto allí también asistieron las asociaciones de mutualidades. Los asistentes decidieron juntar todos los esfuerzos y se creó el Consejo Canadiense de la Cooperación y la Mutualidad (СССM).

Es muy importante entender que cada una de estas integraciones contempla, a su vez, otro conjunto. En el caso de Québec, el Consejo comprende once diferentes asociaciones o federaciones de integración regional.

\section{Las integraciones del País Vasco}

Por su carácter estrictamente regionalista, el cooperativismo del País Vasco constituye un movimiento cooperativo independiente en España. Generalmente creemos que allí sólo hace presencia la experiencia Mondragón, confusión que es aceptada por el hecho de ser la más publicitada y la que se emula en otras subregiones del País Vasco y en otras provincias de España.

La estructura de gobierno de MCC representa el esquema organizacional base de los demás modelos. Antes de explicar la organización de la integración vasca, es indispensable reconocer los siguientes elementos del proceso que se sigue en cada uno de sus modelos.
Ya hemos visto que la Corporación Mondragón se configura en cuatro grandes áreas: finanzas, industria, distribución y conocimiento, que funcionan autónomamente dentro de una estrategia de conjunto, coordinada desde un centro corporativo. Este último, desde el punto de vista organizacional, son los organismos sociales y directivos compuestos por el Congreso Cooperativo, la Comisión Permanente y el Consejo General.

El Congreso Cooperativo tiene como función establecer los criterios estratégicos por los que se administrará la Corporación, mediante la planificación y coordinación de sus unidades de negocio; está compuesto por 650 congresistas, delegados por las cooperativas, y se reúne ordinariamente cada año. El Congreso Cooperativo es el órgano supremo de soberanía y representación de la Corporación, equivalente a su gran Asamblea General. Sus decisiones afectan a todas las cooperativas asociadas. En la actualidad, el sistema tiene 256 empresas y organizaciones, de las que aproximadamente la mitad son cooperativas.

La Comisión Permanente es un cuerpo colegiado que gobierna la Corporación por delegación del Congreso Cooperativo. Su función básica es la de impulsar y controlar la ejecución de las políticas y los acuerdos adoptados por el Congreso, ejerciendo un seguimiento continuado de la evolución del modelo y de la gestión de la Presidencia del Consejo General. La Comisión la integran 19 miembros elegidos en representación de las distintas Divisiones de la Corporación. 
El Consejo General es el cuerpo colegiado responsable de la elaboración y aplicación de las estrategias y objetivos corporativos; coordina las políticas de las diferentes divisiones y cooperativas, y actúa de manera permanente. Lo conforman el Presidente del Consejo General (Presidente de la Corporación) y 14 vicepresidentes. Al frente de cada División se halla un vicepresidente corporativo.

La cooperativa individual constituye el nivel básico de la estructura organizativa del sistema Mondragón, con su Asamblea General, como órgano supremo de expresión y soberanía, y su Consejo Rector como órgano máximo de gestión y representación, responsable de la elección del director gerente. Las cooperativas que operan en un mismo sector empresarial configuran una agrupación sectorial que, a su vez, se integra en la división correspondiente.

Ahora bien, la Corporación Mondragón forma parte de una estructura vertical de representación: la Federación de Cooperativas de Trabajo Asociado y la Confederación.

La Confederación de Cooperativas de Euskadi (Konfekoop) es una entidad que engloba a las Federaciones Sectoriales que existen en Euskadi. Se creó en 1996 por la necesidad que había de fortalecer el movimiento regional, dada su importancia tanto económica como social. Las cooperativas presentes en los diversos sectores de actividad se integraron en federaciones sectoriales para defender sus intereses y su representación. Hasta finales del siglo xx existían seis federa- ciones: de consumo, agrarias, de crédito, educacionales, de trabajo asociado y de transportes. En el 2006 se da un proceso de fusión entre varias de ellas, con el espíritu de aprovechar sinergias y aunar servicios, de manera que Konfekoop quedó compuesta por las cuatro federaciones resultantes del proceso:

- Federación de Cooperativas de Consumo de Euskadi (1988).

- Federación de Cooperativas Agrarias de Euskadi (1989).

- Federación de Cooperativas de Transportistas de Euskadi (1992).

- Federación de Cooperativas de Trabajo Asociado, Enseñanza y Crédito de Euskadi (2006), denominada Erkide.

\section{Características básicas de las experiencias}

De la relación de integraciones sociales observadas, se pueden apreciar algunas características básicas de las mismas, a saber:

- Se producen integraciones sectoriales - por actividad económica- o de cobertura sectorial —especializando áreas comunes-, en los órdenes regionales, que se agregan a estructuras de representación regional.

- Se producen integraciones por naturaleza en los órdenes regionales, que agrupan cooperativas de base y agrupaciones sectoriales, que luego se agregan a estructuras nacionales.

- Existen confederaciones regionales (o consejos), que pueden agrupar las diferentes expresiones de integración por naturaleza o actividad económica. 
- Las integraciones más fuertes se ubican en territorios claramente identificados (geográfica o culturalmente), que pueden ser estados o provincias, estableciendo confederaciones propias, pero siempre estarán integradas a confederaciones más amplias.

- Todas estas integraciones comprenden un evento periódico - anual o de cada dos o cuatro años- que denominan Congreso de la Cooperación - a la manera de una asamblea general del movimiento-, encargado de orientar la política general de desarrollo.

- Todas las integraciones comprenden una estructura de mando - político y económico- que hace realidad las orientaciones del Congreso.

- Entre sus funciones se encuentran las de representación y capacitación.

\section{Conclusión}

Los movimientos cooperativos surgidos luego del éxito del experimento de Rochdale han respondido a las exigencias de su tiempo y de sus entornos, nacionales o regionales, mediante dos expresiones básicas de integración: de un lado, las que presentan fines de contenido social y moral; de otro, las que se definen en el ámbito económico. Estas han sido formas clásicas de integración del cooperativismo universal, pero con el paso de los años, para superar la fragmentación cooperativa, se fue fraguando una nueva dinámica relacionada con la aspiración de conquista, tal como lo definiera alguna vez Paul Lambert: la dinámica de la intercooperación. De esta forma, la integración alcanzó una nueva dimensión, siendo una de las formas más eficaces para superar las graves limitaciones de un medio externo en transformación.

De las experiencias históricas aquí descritas, se pueden colegir las siguientes conclusiones básicas:

Primera: para avanzar hacia la formación de un cooperativismo con sinergias y en redes, se requiere, en primer término, una intensa interdependencia entre las diferentes ramas productivas, ya que no se concibe ubicado exclusivamente en parciales y fragmentarias actividades económicas; necesariamente, un cooperativismo que se conciba avanzado, debe intervenir la producción en todas sus fases e interconectar las diferentes unidades productoras.

Segunda: para cumplir el papel histórico que ha tenido el cooperativismo (ser coadyuvante en la formación de condiciones de equidad social y económica), es necesario que haya un compromiso con el desarrollo mismo del sector y con el del medio socioeconómico que lo rodea. Es la única manera de constituirse en un sector económico alternativo con impacto en la vida local y regional.

Tercera: el vínculo territorial es definitivo para el desarrollo del cooperativismo, rompiendo el círculo vicioso del endogenismo asociativo. Ello supone la formación de circuitos económicos de base cooperativa en cada microrregión y en cada subregión, de modo que el crecimiento del cooperativismo está ligado a las condiciones y necesidades de cada territorio específico. 
Cuarta: la intercooperación se produce inicialmente en los ámbitos sectoriales e intrasectoriales, haciendo posible la formación de una economía que retiene el valor agregado producido por las mismas cooperativas, fuente vital para lograr una mayor generación de ingresos y una distribución equitativa de estos.

En definitiva, los movimientos de cooperación que alcanzan la madurez, en tránsito hacia la construcción de un nuevo mundo para las futuras generaciones, son aquellos que se reconocen a sí mismos, descubriendo sus ventajas competitivas, maximizando sus potencialidades y logrando autoestima. Así se convierten en una fuerza poderosa y arrolladora que dinamiza la vida econó- mica y ciudadana, transformando el medio ambiente que le circunda.

\section{Referencias}

Del Arco Álvarez, J.L. (1977). Cooperativismo: una filosofía, una técnica. Zaragoza: CNEC.

Desroche, H. (1977). El desarrollo intercooperativo. Buenos Aires: Intercoop.

Martínez Charterina, A. (1990). Análisis de la Integración Cooperativa. Bilbao: Universidad de Deusto.

Ormaechea, J. M. (1988). El cooperativismo de grupo ante el reto europeo. Valencia: Grupo Empresarial Cooperativo de Valencia.

Rojas Coria, R. (1989). Las sociedades cooperativas de producción en México. Cooperativismo de Producción y Trabajo. Medellín: Asacoop. 